\title{
Metastable Solvent Epitaxy of SiC, the Other Diamond Synthetics
}

\author{
Shigeto R. Nishitani ${ }^{1}$, Kensuke Togase ${ }^{1}$, Yosuke Yamamoto ${ }^{1}$, \\ Hiroyasu Fujiwara ${ }^{2}$, and Tadaaki Kaneko ${ }^{3}$ \\ ${ }^{1}$ Kwansei Gakuin University, Department of Informatics, \\ ${ }^{2}$ (Late) Kyoto University, Department of Energy Science, \\ ${ }^{3}$ Kwansei Gakuin University, Department of Physics,
}

Japan

\section{Introduction}

Professor W. Shockley, a Nobel prize winner and the 'father' of the transistor, predicted in the 1950s that $\mathrm{SiC}$ would soon replace $\mathrm{Si}$ in devices because of its superior material properties(Cited from Choyke, 1960). His prediction, however, has not yet come true because of the high cost of manufacturing $\mathrm{SiC}$ wafers. The current price of 2-inch $\mathrm{SiC}$ wafers is close to that of diamond jewellery rather than to that of Si wafers. Nevertheless, owing to its promising physical properties for high-power devices and for achieving significant reductions in $\mathrm{CO}_{2}$ emission, many researchers and companies are purchasing many $\mathrm{SiC}$ wafers(Madar, 2004; Nakamura et al., 2004). Very recently, the present authors reported a novel process for fabricating epitaxial SiC(Nishitani \& Kaneko, 2008). This process has the potential to cost less and to provide $\mathrm{SiC}$ wafers with high crystalline quality. Here we present a new synthesis process for manufacturing $\mathrm{SiC}$. In this process, the driving force for crystal growth is elucidated by considering a similarity-the coexistence of the stable and metastable phases-with the diamond synthesis process reported by Bonenkirk et al. (1959) of General Electric.

In this review, the authors introduce the experimental procedures and the results of this novel process of making stable phase of $\mathrm{SiC}$ at first. Then they will show the speculated mechanism from the thermodynamical point of view, especially the concept of the double phase diagram and the concentration profile. In the end, understanding the phase stability of many polytypes of $\mathrm{SiC}$, the reported phase diagrams, the difficulty of the equilibrium state achievement, and the results of the first principles calculations will be discussed.

\section{Experimental results}

\subsection{Conventional methods}

While SiC was first synthesized by Acheson at the end of the 19th century(Acheson, 1896), single-crystal wafers of $\mathrm{SiC}$ became commercially available only in the early 1990s. Boules of other important semiconductors such as $\mathrm{Si}$, GaAs and InP are manufactured through a liquid process, while those of $\mathrm{SiC}$ are produced through a vapor process. Owing to the 
peritectic reaction of $\mathrm{SiC}$ at above $2500{ }^{\circ} \mathrm{C}$ as shown in the phase diagram of Fig. 1, growth from a stoichiometric melt is not possible at normal pressure. The incongruent compounds are usually produced by the solution method. The low carbon solubility in liquid Si leads to insufficient mass transport of $\mathrm{C}$, and this in turn results in the crystal growth in the Si-C solution method being quite slow(Hofmann \& Müller, 1999). The solution method provides crystals with better crystallinity and a smaller defect density as compared to vapor methods. Thus, the solution method is preferred for preparing SiC(Hofmann \& Müller, 1999). Many attempts have been made to increase the carbon solubility in liquid Si, especially by the addition of metallic elements or the application of high pressures. Nevertheless, the productivity of such methods does not exceed that of the vapor methods(Casady \& Johnson, 1996; Chaussende et al., 2007; Hofmann \& Müller, 1999; Wesch, 1996).

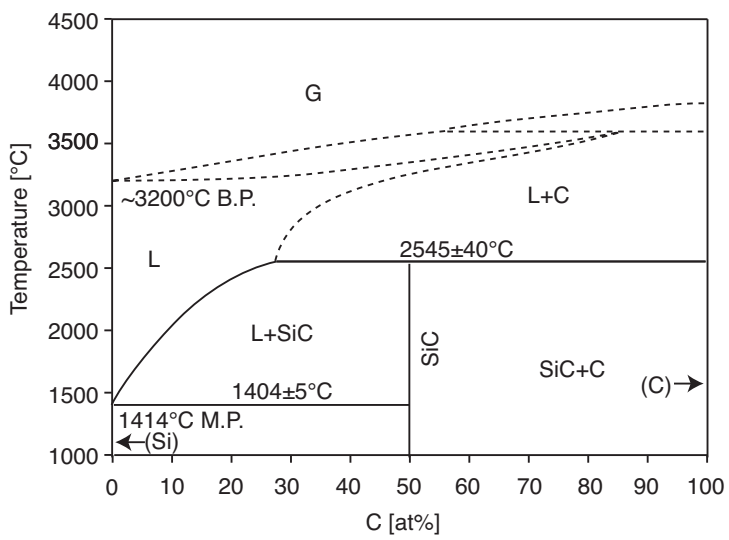

Fig. 1. Phase diagram of Si-C binary system(Olesinski \& Abbaschian, 1996).

Among the vapor processes, the sublimation process, which is schematically illustrated in Fig. 2a and which was first proposed Tairov \& Tsvetkov (1978), is the standard process used for the commercial manufacture of $\mathrm{SiC}$. In this process, the source powder and a seed crystal are placed in a graphite crucible. $\mathrm{SiC}$ powder is then heated to typically $2400{ }^{\circ} \mathrm{C}$ and allowed to sublimate. $\mathrm{Si}$ and $\mathrm{C}$ vapors are transferred in an inert gas, and they recrystallize on a slightly cooler single-crystal seed. The temperature dependency of the crucible is schematically shown in the left-hand panel of Fig. 2a. The main drawback of this method is that the obtained boules contain many types of grown-in defects, such as micropipes, step bunching, dislocations and stacking faults. For the reduction of these defects, the operation parameters such as the growth temperature, gas flow rate and total pressure should be controlled quite steadily for a long operation time. This long and sensitive operation performed at a high temperature and involving a temperature gradient makes $\mathrm{SiC}$ wafers expensive. Researches on alternative processes such as chemical vapor deposition and the vapor-liquid-solid process are continuing with the objective of improving the growth rate and crystal quality(Chaussende et al., 2007).

\subsection{Metastable solvent epitaxial method}

Our proposed method employs the solution growth technique. A schematic drawing of the apparatus is presented in Fig. 2b. In this method, C is transferred through liquid Si instead of Ar gas, which is used in the conventional method. Poly-crystalline 3C-SiC source and sigle-crystalline $4 \mathrm{H}-\mathrm{SiC}$ plate are placed in a $\mathrm{TaC}$ crucible and liquid $\mathrm{Si}$ solvent is sandwiched 
a

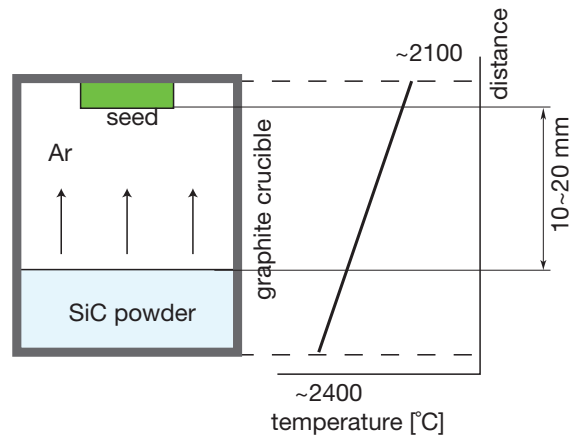

b

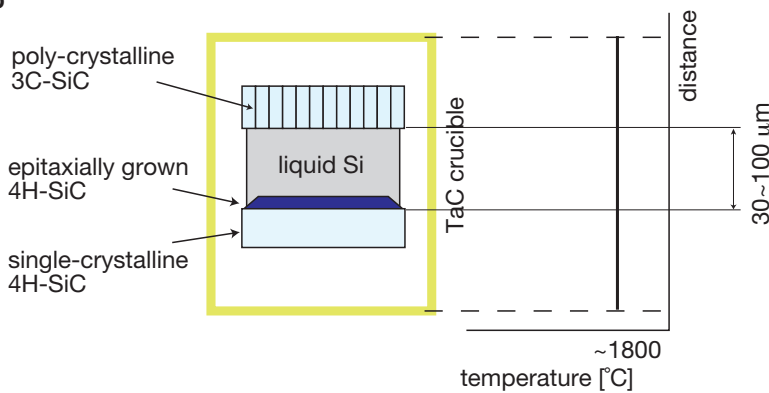

Fig. 2. Schematic illustrations of $\mathbf{a}$ the conventional sublimation method and $\mathbf{b}$ the new solvent method for the preparation of $\mathrm{SiC}$. Their setups are similar and comprise the sources ( $\mathrm{SiC}$ powder and polycrystalline 3C-SiC), transfer media (Ar and liquid $\mathrm{Si}$ ), produced crystals (the seed and $4 \mathrm{H}-\mathrm{SiC}$ fine particles) and crucibles (graphite and $\mathrm{TaC}$ ). The characteristic differences are in the thicknesses and the temperature profiles of the transfer media, as illustrated in the panels on the right-hand side.

between them. The solvent is a very thin layer with a thickness of $30 \sim 100 \mu \mathrm{m}$. The temperature inside the crucible is held constant.

After holding at the growth temperature of $1800^{\circ} \mathrm{C}$ for $10 \mathrm{~min}$, the newly grown $4 \mathrm{H}-\mathrm{SiC}$ layer is observed on the original $4 \mathrm{H}-\mathrm{SiC}$ single-crystalline plate as shown in Fig. 3(Nishitani \& Kaneko, 2008). The scanning electron microscopy image shows the transverse section of a sample with the sandwiched structure of $\mathrm{SiC}$ and $\mathrm{Si}$ layers. Because the substrate of $4 \mathrm{H}-\mathrm{SiC}$ is $\mathrm{n}$-doped, the newly grown $4 \mathrm{H}-\mathrm{SiC}$ layer is easily distinguished from the original substrate. The feed of polycrystalline 3C-SiC was dense before the operation. Its boundaries dissolve preferentially, and it becomes porous during the operation. The wave dispersion X-ray (WDX) profile of carbon in Fig. 3 shows a concentration of $50 \%$ in the $\mathrm{SiC}$ layers and almost zero in the Si solvent. Upon reversing the configuration of $3 \mathrm{C}$ - and $4 \mathrm{H}-\mathrm{SiC}$ plates, $4 \mathrm{H}-\mathrm{SiC}$ grew epitaxially again, which indicates that no unintentional temperature gradient occurs in the crucible; thus, the temperature gradient cannot be the driving force of the solvent movement.

In the case of replacing the single-crystalline $4 \mathrm{H}-\mathrm{SiC}$ to poly-crystalline $3 \mathrm{C}-\mathrm{SiC}$ in the configuration of Fig. $2 \mathrm{~b}$, many fine particles with diameters of 30 300 $\mu \mathrm{m}$ are observed to be produced on the both sides of polycrystalline $3 \mathrm{C}-\mathrm{SiC}$ source plates, as shown in Fig. $4 \mathrm{a}$. Multifaceted crystals grow like mushrooms and no grain boundaries are observed in them. 


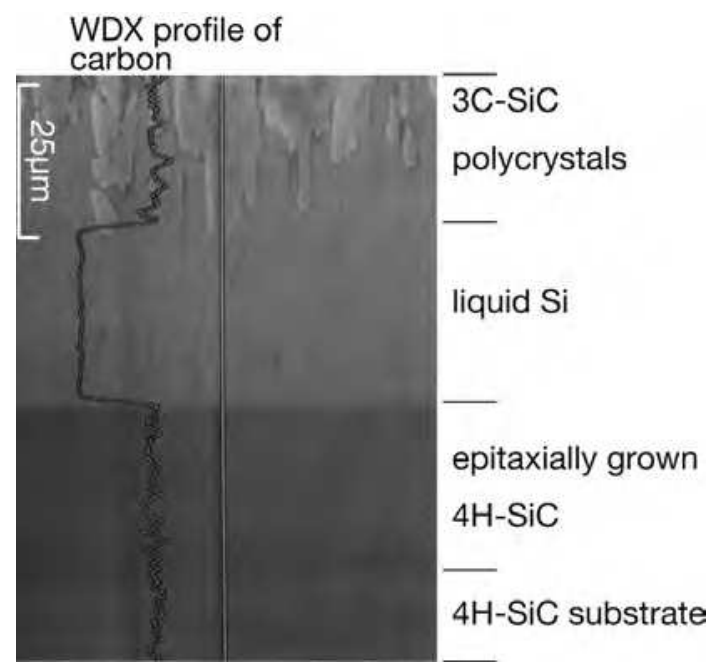

Fig. 3. Scanning electron microscopy image and wave dispersion X-ray (WDX) profile of carbon of epitaxially grown $4 \mathrm{H}-\mathrm{SiC}$ in the transverse section of a sample with the sandwiched structure of SiC and Si layers(Nishitani \& Kaneko, 2008).

Figure 4c shows the Raman spectra of the fine crystalline particles and the polycrystalline 3C-SiC substrate obtained using a 488-nm excitation laser at room temperature. The spectra of the substrate show broad peaks at around $768 \mathrm{~cm}^{-1}$ and $797 \mathrm{~cm}^{-1}$, which are typical of 3C-SiC with randomly distributed stacking faults(Rohmfeld et al., 1998-I). On the other hand, the fine particles show a sharp peak at $776 \mathrm{~cm}^{-1}$, which is typical of $4 \mathrm{H}-\mathrm{SiC}$. Thus, we conclude that fine single-crystal $4 \mathrm{H}-\mathrm{SiC}$ particles are crystallized from polycrystalline $3 \mathrm{C}-\mathrm{SiC}$ in the absence of a temperature gradient. $4 \mathrm{H}-\mathrm{SiC}$ crystals grow without a temperature gradient nor a concentration difference between sources and products of $\mathrm{SiC}$.

\section{Speculated mechanism}

\subsection{Solution method}

The origin of the driving force for crystal growth is the same as that in the case of diamond synthesis from a solvent of a metal-carbon binary system. Both the diamond synthesis method and the proposed method for $\mathrm{SiC}$ synthesis are solution growth methods; a typical example of a solution growth method is the method used for the growth of alum crystals, which is very familiar as a topic frequently dealt with in science classes, even in primary schools. Thus, a review of the growth process of alum crystals would be a good starting point for explaining as well as understanding the growth of diamond and $\mathrm{SiC}$ crystals. Large alum single crystals can be obtained as follows. First, alum powder is dissolved in hot water. Next, a seed tied to a long thread is inserted into the solution, and the solution is cooled and left to stand. A crystal starts growing from the seed and develops into a large single crystal.

Figure 5a shows schematic representations of the alum deposition process. The upper panel represents the dissolution of alum in water at a high temperature and the lower panel represents the deposition of alum on the seed at a low temperature. In the system shown in Fig. 5b, the source and seed are sandwiching the water solution; a temperature gradient is applied in the water solution. This is the setup in the so-called solvent zone technique, 
a

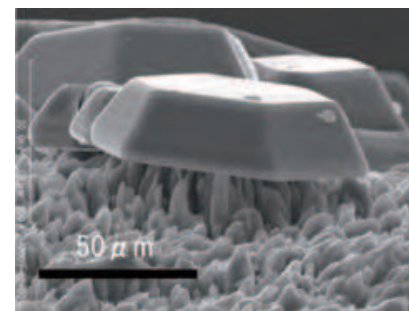

C

b

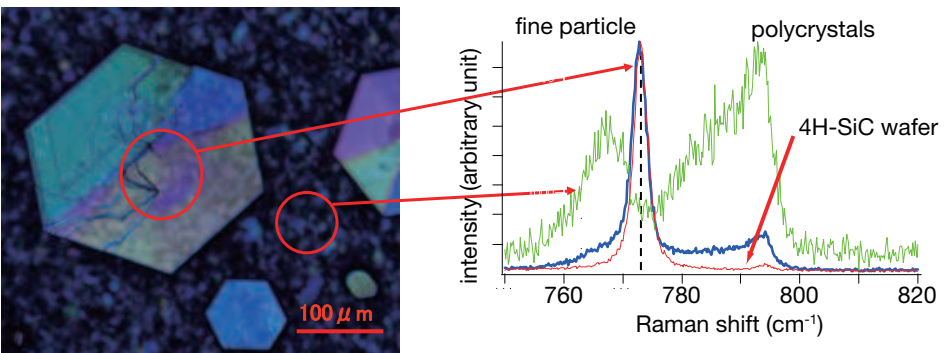

Fig. 4. a Side view and $\mathbf{b}$ top view of fine particles on the polycrystalline 3C-SiC source plate and $\mathbf{c}$ Raman spectra of the regions in $\mathbf{b}$ indicated by the circles. $\mathbf{a}$ is a scanning electron microscopy image and $\mathbf{b}$ is an optical microscopy image. The spectrum of the single-crystal $4 \mathrm{H}-\mathrm{SiC}$ wafer is also shown in $\mathrm{c}$ as a standard.

where dissolution and deposition occur simultaneously. The driving force for crystal growth is supersaturation, which can be schematically explained by considering the solubility limit of alum or the so-called phase diagram of an alum-water system.

a

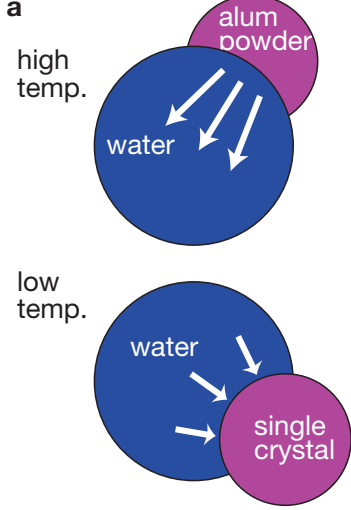

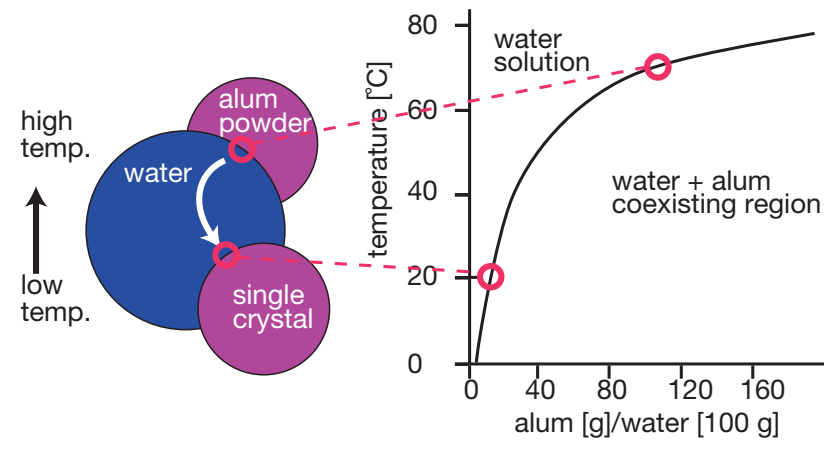

Fig. 5. Schematic drawings of $\mathbf{a}$ alum deposition and $\mathbf{b}$ the solvent zone technique in which a temperature gradient is present; $\mathbf{c}$ the phase diagram of the potassium alum-water system. In $\mathbf{a}$ and $\mathbf{b}$, the vertical positions of the alum powder (source), water (solvent) and single crystal (seed) represent their relative energies or chemical potentials.

The solubility of potassium alum in water is measured as shown in Fig. 5c. The solubility limit, or liquidus of alum, separates the water solution region from the region where water and alum 
coexist. As the temperature increases, the solubility limit shifts to higher alum contents. At $80{ }^{\circ} \mathrm{C}, 321 \mathrm{~g}$ of potassium alum dissolves in $100 \mathrm{~g}$ of water. Such a solution can be cooled to a temperature where the solubility limit is considerably low, and it is called a supersaturated solution. At lower temperatures around the seed crystal, the small solubility limit facilitates the deposition of alum on the seed crystal. As marked in Fig. 5c, the temperature gradient between the source and the seed alum results in different solubility limits around them; this difference is the driving force for the dissolution and deposition of alum.

\subsection{Double phase diagram}

Although diamond synthesis in a metal-carbon system at high pressures is slightly complex, it is based on the same mechanism as that of alum deposition. The initial materials used for diamond synthesis in the original General Electric process were graphite and group VIII transition metals(Bonenkirk et al., 1959). At a high pressure and a high temperature, metal melts and comes into contact with graphite. The liquid metal was initially thought to function as a catalyst by the workers at General Electric, but was later clarified to act as a transport medium by Giardini and Tydings(Giardini \& Tydings, 1962). Similar to Fig. 5b, a schematic drawing of a diamond synthesis system is shown in Fig. 6a. The liquid metal that is commonly used in diamond synthesis is $\mathrm{Ni}$; the $\mathrm{Ni}-\mathrm{C}$ phase diagram at $54 \mathrm{Kbar}$ is shown in Fig. 6b(Strong \& Hanneman, 1967). Although the graphite phase is the only stable phase at normal pressure, at $54 \mathrm{Kbar}$, the diamond phase is stable below $1740 \mathrm{~K}$. Liquid Ni coexists with the diamond phase between $1667 \mathrm{~K}$ and $1728 \mathrm{~K}$. Thus, the solution growth of diamond from liquid $\mathrm{Ni}$ is possible in this temperature range. The true trick in diamond synthesis is not the 'stability' of the diamond phase, but the 'metastability' of the graphite phase, as indicated by the dashed lines in Fig. 6b. The synthetic capsule in high-pressure anvils is small and it is very difficult to manage sensitive temperature gradients. Thus, each process of crystal growth, i.e. the melting of metastable graphite in liquid $\mathrm{Ni}$, carbon transfer within the solvent and crystallization of stable diamond on the seed, occurs in a very small temperature range. The driving forces for these reactions cannot be obtained from the temperature gradient, but can be obtained from the difference in the stability between graphite and diamond. For example in Fig. $6 \mathrm{~b}$, at $1700 \mathrm{~K}$, the solubility of metastable graphite in liquid Ni represented by the dashed line is higher than that of stable diamond denoted by the solid line. The driving force for the crystal growth of the alum shown in Fig. 5 is generated when there is a spatial or temporal temperature difference, but that in diamond synthesis can be produced even at a constant temperature.

Figure $6 \mathrm{~b}$ shows the so-called double phase diagram that is well known in metallurgy, e.g. the Fe-C system(Hansen \& Anderko, 1958), and that is commonly observed for the systems containing metastable phases(Ishihara et al., 1984-5). The mechanism of crystal growth in the presence of a solubility difference between the stable and metastable phases, which is discussed in the present study, can be observed in the work of Van Lent (1961) on the transformation of mercury/white tin amalgams to gray tin, and it was first elucidated by Hurle et al. (1967) using the so-called thin alloy zone (TAZ) crystallization.

\subsection{Ostwald ripening and concentration profile}

The solution growth is easily understood by the phase diagrams, but the simultaneous growth and dissolution processes of polytypes are hardly recognized. Such a puzzling process can be observed in the Ostwald ripening, which is shown schematically in Figs. 7. Ostwald ripening, also called coarsening, which occurs at the late stage of the precipitation, 
a

b

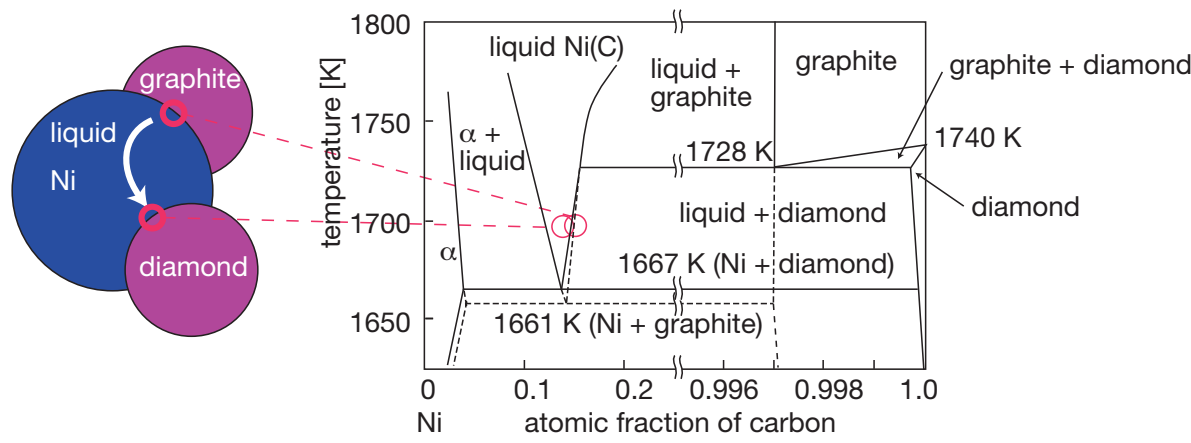

Fig. 6. Schematic drawings of a diamond synthesis and $\mathbf{b}$ enlarged sections of the Ni-C phase diagram at $54 \mathrm{Kbar}$. In a, graphite, liquid $\mathrm{Ni}$ and diamond are the source, solvent and seed, respectively. In $\mathbf{b}$, the stable Ni-diamond and metastable Ni-graphite reactions are represented by solid and dashed lines, respectively(Strong \& Hanneman, 1967).

is driven spontaneously by the diffusion between small (S) and large (L) precipitates due to Gibbs-Thomson effect. In this section, the matrix and precipitate phases are represented as $\alpha$ and $\beta$, respectively. The precipitates show the same composition of $x_{\beta}$ but different pressures of small and large radii, which makes the different free energies, $G_{\beta}^{s}$ and $G_{\beta}^{L}$, as shown in free-energy vs. concentration diagram of Fig. 7a. The common tangents of free-energy curves between matrix solution and precipitates show different angles and touch at the different concentrations $x_{\alpha}^{L}$ and $x_{\alpha}^{S}$ of the free energy curve of the matrix solution. This concentration difference of matrix appears at the interfaces of the precipitates. Fig. $7 \mathrm{~b}$ shows the schematic diagram of the solute concentration profile of the system of $\alpha$ matrix and small(S) and large(L) $\beta$ precipitates. The matrix concentration equilibrating with the small precipitates should be higher than that with the large precipitates. This difference drives the solute diffusion and thus the simultaneous growth and dissolution of precipitates.

\subsection{Direct melting of metastable phases}

Ostwald ripening is the reaction in a solid solutions, which means the life time of metastable phase may be longer at lower temperatures and lower diffusivity. Does such a metastable phase directly melt in liquid?

The typical example of the behavior of the coexistence of stable and metastable phases is observed in the Fe-C system. As mentioned before, the double phase diagram of $\mathrm{Fe}-\mathrm{C}$ and $\mathrm{Fe}^{-} \mathrm{Fe}_{3} \mathrm{C}$ systems is well studied and established. The melting behavior of metastable $\mathrm{Fe}_{3} \mathrm{C}$ phase has investigated in detail by Okada et al. (1981). They measured the differential thermal analysis (DTA) curves for the white, gray and mixture cast irons at the eutectic temperature and composition region. Fig. 8 shows the summarized results of DTA curves as well as the schematic double phase diagram. The endothermic temperatures shift due to the kinetic reason of the measuring apparatus, but the corrected temperatures show the stable and metastable eutectic temperatures of $1426 \mathrm{~K}$ and $1416 \mathrm{~K}$, respectively. The specimens of gray cast iron contains stable phases of graphite and fcc-Fe(autenite), where they all melt only 
a

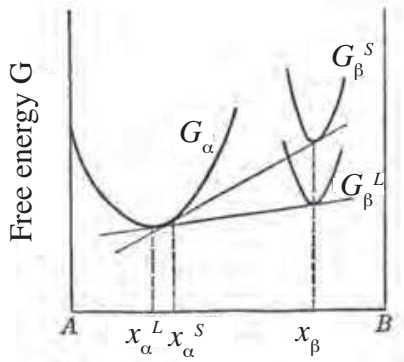

Concentration b

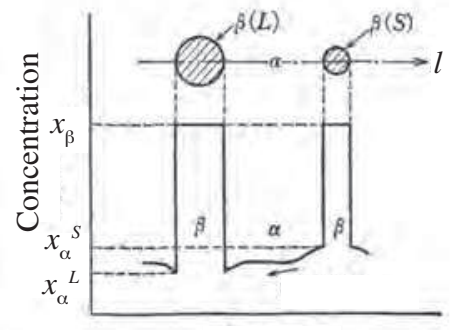

Distance

Fig. 7. Schematic drawings of a free energy vs. concentration diagram and bconcentration profile of the Ostwald ripening.

at the stable eutectic temperature of $1426 \mathrm{~K}$. On the other hand, the specimens of white cast iron shows the double peaks of endothermic reactions at the slow heating rates. Okada et al. (1981) found that at the first peak the metastable $\mathrm{Fe}_{3} \mathrm{C}$ melts but soon graphite solidifies and then remelt at the second peak. At the faster heating rates, only the melting of the metastable $\mathrm{Fe}_{3} \mathrm{C}$ phase occurs. For the specimens of mixture cast iron, the reactions are complicated but the melting and solidifying occur simultaneously. These experimental results indicate that the metastable phase is so stable that can melt directly.

a

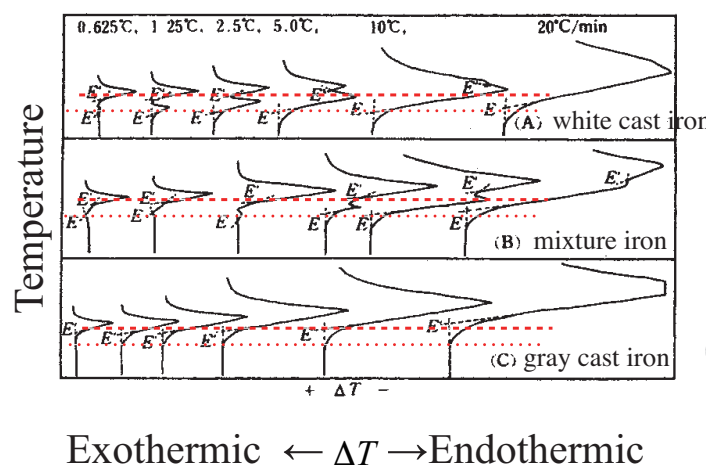

b

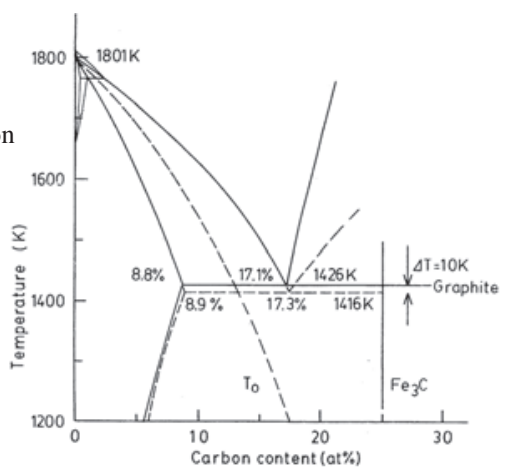

Fig. 8. a DTA curves of cast irons(Okada et al., 1981) and $\mathbf{b}$ the double phase diagram of equiblibrium $\mathrm{Fe}-\mathrm{Graphite}$ and metastable $\mathrm{Fe}^{-} \mathrm{Fe}_{3} \mathrm{C}$ systems.

\subsection{Speculated mechanism}

From the experimental result shown in Fig. 4, $4 \mathrm{H}-\mathrm{SiC}$ is expected to be more stable than 3C-SiC. The Si-C system should show a double phase diagram, as schematically shown in Fig. 9a. The corresponding free-energy vs. concentration diagram is also illustrated in Fig. 9b. 
The solubility limit of each phase is determined by the tangent common to the free-energy curves of the coexisting phases. At the temperature indicated by the dotted line, the solubility limit of metastable $3 \mathrm{C}-\mathrm{SiC}$ is $x_{1}^{3 \mathrm{C}}$, which corresponds to the dashed line of the liquidus in Fig. 9a. The solubility limit of stable $4 \mathrm{H}-\mathrm{SiC}$ is $x_{1}^{4 \mathrm{H}}$, which corresponds to the solid line of the liquidus. The concentration gradient in the layers consisting of 3C-SiC and $4 \mathrm{H}-\mathrm{SiC}$ and a very thin layer of liquid Si in between is obtained. The schematic carbon concentration profile in the liquid Si layer is shown in Fig. 9c. The concentration gradient at the metastable solubility limit of 3C-SiC leads to the extraction of $\mathrm{C}$ from the source plates. This concentration gradient also causes carbon diffusion across the liquid Si solvent and to the interface of the seed, where $\mathrm{C}$ is deposited due to the supersaturation of $4 \mathrm{H}-\mathrm{SiC}$. Although the small solubility limit of $\mathrm{C}$ in liquid $\mathrm{Si}$, which is the cause of the slow growth of $\mathrm{SiC}$ in the conventional liquid method, still remains, the small thickness of the Si solvent in the new method leads to a sufficient concentration gradient for the growth of $4 \mathrm{H}-\mathrm{SiC}$ crystals.

\section{Phase stability of SiC polytypes}

\subsection{Phase diagram assessment of Si-C system}

The key data in order to rationalize this novel process is the phase stability or the hierarchy of $\mathrm{SiC}$ polytypes. The reported phase diagrams, however, are somewhat conflicting.

The standard data book Chase (1998) shows the standard formation enthalpies for $\alpha$ and $\beta$ phases, as follows:

$$
\begin{aligned}
& \Delta_{f} H(\alpha-\mathrm{SiC}, 298.15 K)=-71.546 \pm 6.3 \mathrm{~kJ} / \mathrm{mol} \\
& \Delta_{f} H(\beta-\mathrm{SiC}, 298.15 K)=-73.220 \pm 6.3 \mathrm{~kJ} / \mathrm{mol} .
\end{aligned}
$$

Although the data shows that the $\beta$ (cubic) phase is more stable than the $\alpha$ (hexagonal) phase at $298.15 \mathrm{~K}$, the difference of the measured values are within the measurement errors. The $\alpha$ (hexagonal) phase indicated in Chase (1998) is $6 \mathrm{H}$, but also mentioned that the many polytypes have not been adequately differentiated thermodynamically. The heat capacity and Gibbs free energy are also reported as shown in Fig. 10. The measured values and the adapted functions in Chase (1998) suggest that $\alpha$ (hexagonal) phase is less stable up to $2000 \mathrm{~K}$, and they concluded unlikely the transformation to $\beta$ (cubic) phase at about $2300 \mathrm{~K}$.

The most widely adapted phase diagram should be that by Olesinski \& Abbaschian (1996) as shown in Fig. 1, where the $\beta$ (cubic) phase is more stable than the $\alpha$ (hexagonal) phase at any temperatures below the periodic temperature of the decomposition of $\mathrm{SiC}, 2545^{\circ} \mathrm{C}$. Although the evaluators of Olesinski \& Abbaschian (1996) mentioned nothing on the types of $\alpha$ (hexagonal) phase, the same authors reported the co-existence of polytypes of $\alpha$ phases, $6 \mathrm{H}$, $15 \mathrm{R}$, and $4 \mathrm{H}($ Olesinski \& Abbaschian, 1984). Furthermore, it also mentioned on the report of Verma \& Krishna (1966), the existence of $\alpha$ stability above $2000^{\circ} \mathrm{C}$. On the other hand, Fromm \& Gebhardt (1976) reported the different type of phase diagram as shown in Fig. 11, where the phase transition from $\beta$ to $\alpha$ phases occurs at around $2000^{\circ} \mathrm{C}$.

Solubilities of carbon in liquid silicon measured by Hall (1958), Scace \& Slack (1959), Dash (1958), Dolloff (1960), Nozaki et al. (1970), Oden \& McCune (1987), Suhara et al. (1989), Kleykamp \& Schumacher (1993), Iguchi \& Narushima (1993), Ottem (1993), and Yanabe et al. (1997) are summarized as in Figs. 12. Two reported phase diagrams as shown in Fig. 1 and Fig. 11 are based on the data given by Dolloff (1960). Dolloff (1960)'s data, however, are distinctively different from the others, where the solubility limits are larger than the others. 


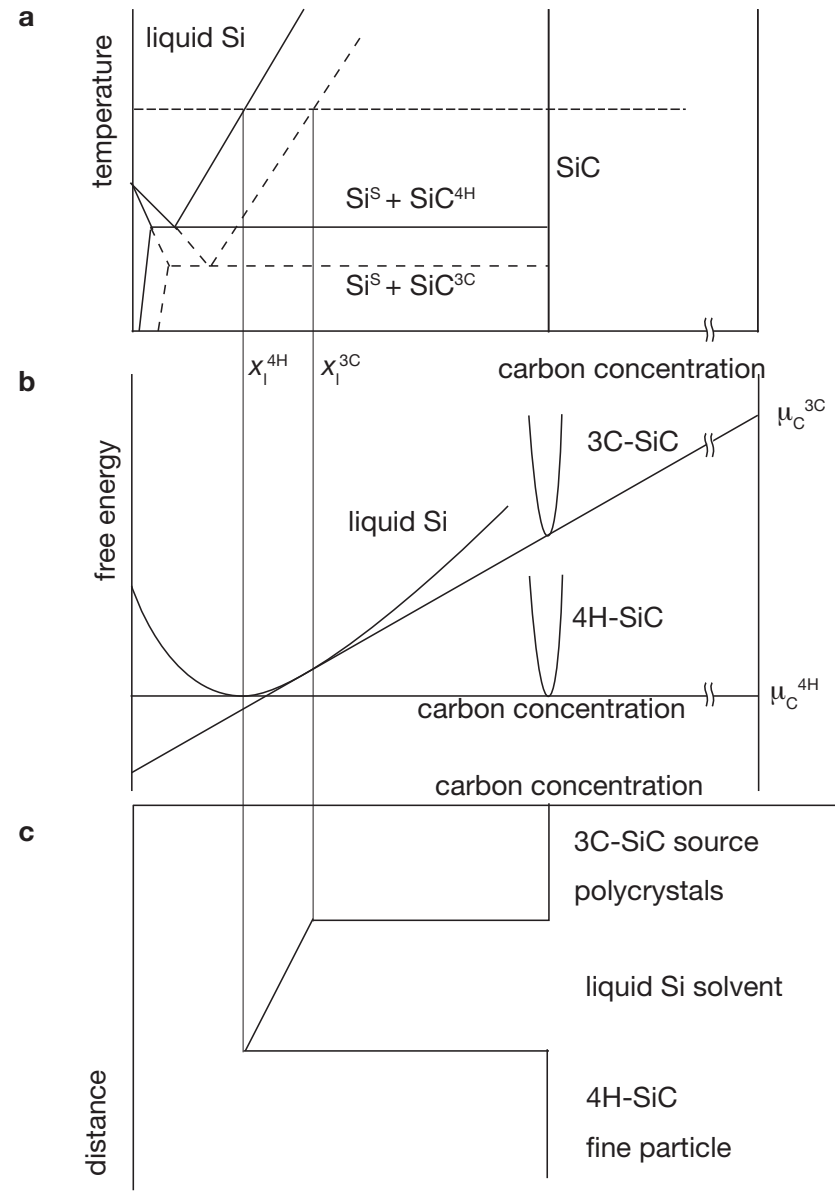

Fig. 9. Schematic drawings of $\mathbf{a}$ the predicted Si-C double phase diagram, $\mathbf{b}$ related free-energy vs. concentration diagram and c carbon concentration profile in the liquid $\mathrm{Si}$ solvent between the $3 \mathrm{C}-\mathrm{SiC}$ source and the $4 \mathrm{H}-\mathrm{SiC}$ fine particles. The metastable eutectic temperature of the reaction liquid $\mathrm{Si} \rightarrow \mathrm{Si}^{\mathrm{S}}+\mathrm{SiC}^{3 \mathrm{C}}$ is lower than the stable eutectic temperature of the reaction liquid $\mathrm{Si} \rightarrow \mathrm{Si}^{\mathrm{S}}+\mathrm{SiC}^{4 \mathrm{H}}$, where $\mathrm{Si}^{\mathrm{S}}$ denotes solid $\mathrm{Si}$. The chemical potentials of $\mathrm{C}, \mu_{\mathrm{c}}$, are given by the intersections of the common tangents with the pure-carbon line in $\mathbf{b}$, and are spatially different in the liquid Si solvent contacting with $3 \mathrm{C}-\mathrm{SiC}$ and $4 \mathrm{H}-\mathrm{SiC}$ in $\mathrm{c}$. The configuration of $\mathrm{c}$ is related to that of the panel on the left-hand side in Fig. 2b. 

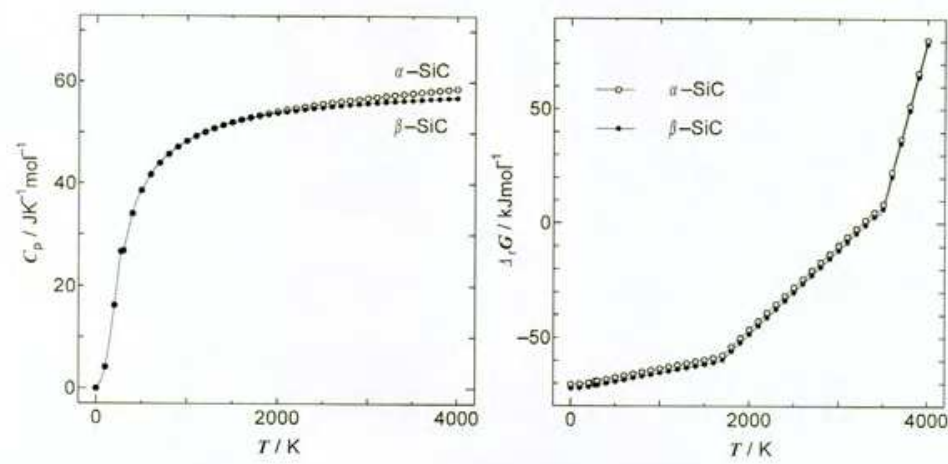

Fig. 10. Heat capacity and Gibbs energy of $\mathrm{SiC}($ Chase, 1998).

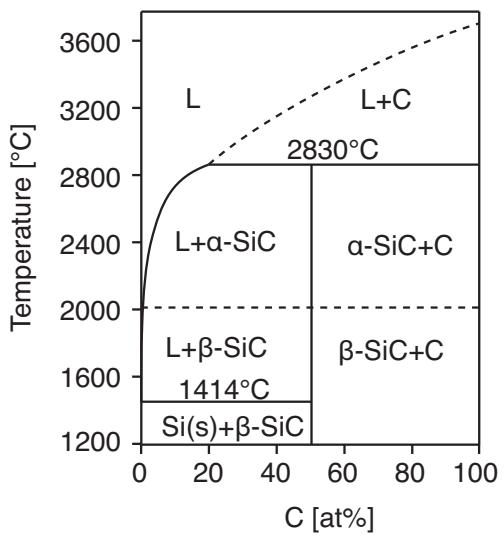

Fig. 11. Phase diagram of Si-C binary system including the phase transition from $\beta$ to $\alpha$ phase around $2000^{\circ} \mathrm{C}$ (Fromm \& Gebhardt, 1976).
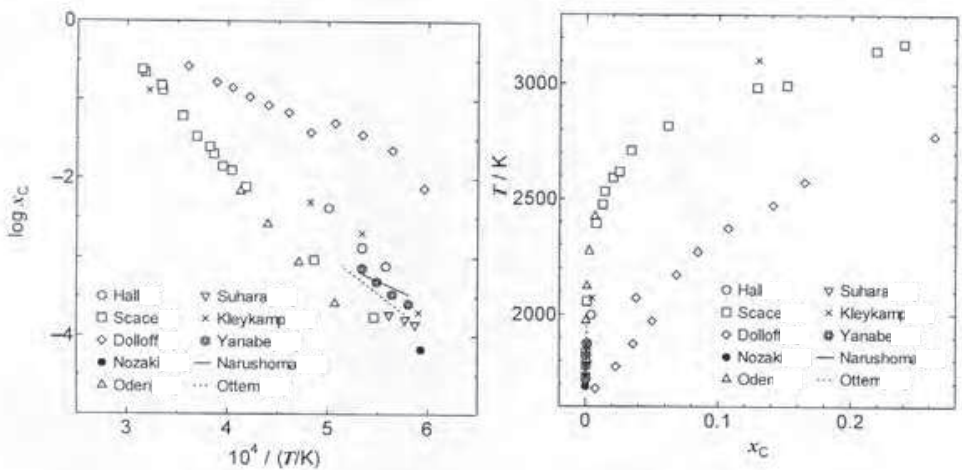

Fig. 12. Solubility of carbon in liquid silicon. 
The reported phase stability between $\alpha$ (hexagonal) and $\beta$ (cubic) might be $6 \mathrm{H}$ and 3C. If this assumption is true, $4 \mathrm{H}$ stability has not been shown experimentally. Furthermore, the distinct difference of solubility limits indicates that the coexistence of stable and metastable phases.

\subsection{Difficulty of the equilibrium state}

Although the conflicts of phase diagrams shown above remain, there have been many attempts of experimental and theoretical researches on the kinetic process of crystal growth of $\mathrm{SiC}$ polytypes. Famous stability diagrams of $\mathrm{SiC}$ polytypes proposed by Knippenberg (1963) and Inomata et al. (1968) show that the crystalized phases are controlled both by the temperature and growth rate of the operations.

The limit to slow growth rate of kinetic processes or results of long period holding should be equal to static results. But it is very difficult to dissolve whole amount of $\mathrm{SiC}$ crystals due to small solubility limit of $\mathrm{SiC}$ in liquid $\mathrm{Si}$. If there remain seeds of metastable phases during the previous processes, it is difficult to remove all of them. The metastable phase also grows due to the co-exsitence of less stable phases as shown in Ostwald ripening, or from super-saturated liquid Si. Furthermore, the required high temperature and inert environment make the static conditions very difficult.

Inomata et al. (1969) performed careful experimental observations on the relationship between the polytypes of $\mathrm{SiC}$ and the supersaturation of the solution at $1800^{\circ} \mathrm{C}$ with the solution method, and have shown the following results;

1. $\beta$-SiC crystallizes from highly supersaturated solution. The crystals obtained at the condition of low supersaturation, however, consist of mainly $\alpha$-SiC such as $4 \mathrm{H}, 15 \mathrm{R}$ and $6 \mathrm{H}$.

2. Relative amount of $4 \mathrm{H}$ increased markedly with decreasing the supersaturation.

3. From the results stated above, it is concluded that $4 \mathrm{H}$ is the most stable structure at $1800^{\circ} \mathrm{C}$ among the basic polytypes of $\mathrm{SiC}, 3 \mathrm{C}, 4 \mathrm{H}, 15 \mathrm{R}$ and $6 \mathrm{H}$.

Those results indicate that the difference between $4 \mathrm{H}$ and $6 \mathrm{H}$ is crucial for determining the hierarchy of $\mathrm{SiC}$ polytypes.

Izhevskyi et al. (2000) summarized not only the kinetic observations, but also pointed out the impurity effects, especially nitrogen affects the transformations among $6 \mathrm{H}, 3 \mathrm{C}$ and $4 \mathrm{H}$ $\mathrm{SiCs}$. Not only through the contamination of the higher temperature operations, but also from the starting materials made by Acheson method, specimens contain non-negligible nitrogen. Very recent improvements on materials and apparatuses make it possible to avoid nitrogen inclusions and get the hierarchy of pure $\mathrm{SiC}$ polytypes experimentally soon.

\subsection{First principles calculations}

For some cases of hardly measuring experimental value, the first principles calculations give some hints of the puzzles, and have been applied on the topic of the hierarchy of SiC polytypes. Liu \& Ni (2005) have summarized the results of the first principles calculations of $\mathrm{SiC}$. All calculations show that $\beta-\mathrm{SiC}$ is less stable than $\alpha-\mathrm{SiCs}$ of $2 \mathrm{H}, 4 \mathrm{H}$ and $6 \mathrm{H}$. The hierarchy between $4 \mathrm{H}$ and $6 \mathrm{H}$ is subtle; two of nine calculations shows that $6 \mathrm{H} \mathrm{SiC}$ is most stable, but the majority of the results indicates that $4 \mathrm{H} \mathrm{SiC}$ is most stable. Of course the calculating results should be judged by the precisions, the energy differences, however, are too small from 0.2 to $2 \mathrm{meV} / \mathrm{Si}-\mathrm{C}$ pair to identify. Although the reliability of the first principles calculations of the hierarchy of $\mathrm{SiC}$ polytypes are insufficient, it is important that the calculating results show against the experimental results. Those are ground state results, which means that is 
only reliable at low temperatures. For including the finite temperature effect, the vibrational entropy effect is crucial, because the configurational entropies should be similar among these $\mathrm{SiC}$ polytypes due to the similar local configurations of tetrahedrons. One calculating result including the vibrational effect is shown by Nishitani et al. (2009) as in Fig. 13.

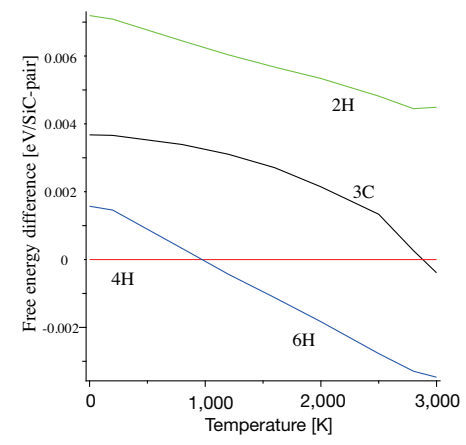

Fig. 13. First principles calculations of temperature dependency of free energy difference of $6 \mathrm{H}, 3 \mathrm{C}$, and $2 \mathrm{H}$ against $4 \mathrm{H} \mathrm{SiC}$ (Nishitani et al., 2009). Finite temperature effects are included through the vibrational free energy calculated by Phonon codes(Medea-phonon, n.d.;

Parlinski et al., 1997).

These first principles calculations were carried out using the Vienna Ab initio Simulation Package (VASP) code(Kresse \& Furthmüller, 1996a;b; Kresse \& Hafner, 1993; 1994). The interaction between the ions and valence electrons was described by a projector augmented-wave (PAW) method(Kresse \& Joubert, 1999). A plane-wave basis set with a cutoff of $400 \mathrm{eV}$ was used. The exchange-correlation functional was described by the generalized gradient approximation (GGA) of the Perdew-Wang91 form(Perdew \& Wang, 1992). Phonon calculation was performed by a commercial pre-processor of Medea-phonon(Medea-phonon, n.d.) with the direct method developed by Parlinski et al. (1997). The volumes and/or c/a ratios were fitted to the most stable point at each temperature.

Fig. 13 shows the temperature dependencies of free energy of $6 \mathrm{H}, 3 \mathrm{C}$, and $2 \mathrm{H} \mathrm{SiC}$ polytypes measured from $4 \mathrm{H} \mathrm{SiC} .4 \mathrm{H} \mathrm{SiC}$ is most stable at low temperatures, but $6 \mathrm{H} \mathrm{SiC}$ is most stable at higher temperatures. $3 \mathrm{C} \mathrm{SiC}$ is less stable against $4 \mathrm{H}$ or $6 \mathrm{H} \mathrm{SiC}$ except at very high temperature region. Those results are consistent with the other speculations but the precisions of the calculations are not enough. Although the more precise calculations will alter the results of hierarchy of polytypes, their result pointed out the possibility of the phase transition in the $\mathrm{Si}-\mathrm{C}$ system from the first principles calculations.

\section{Conclusions}

We have utilized a new method for manufacturing $\mathrm{SiC}$ from liquid $\mathrm{Si}$; in this method, single crystals of $4 \mathrm{H}-\mathrm{SiC}$ are obtained from polycrystalline $3 \mathrm{C}-\mathrm{SiC}$ source in the absence of a temperature gradient. The origin of the driving force for crystal growth is the same as that in the case of diamond synthesis from a metal-carbon solvent, and it is elucidated by considering the stable-metastable double phase diagrams. This similarity in the growth mechanism indicates that the methods developed for diamond synthesis can be directly used for growing large-size $\mathrm{SiC}$ crystals from a metastable solvent of Si. 


\section{References}

Acheson, A. G. (1896). Production of artificial crystalline carbonaceous materials, U.S. Patent Number 492767.

Bonenkirk, H. P., Bundy, F. P., Hall, H. T., Strong, H. M. \& Wentorf, R. H. (1959). Preparation of diamond, Nature 184: 1094-1098.

Casady, J. B. \& Johnson, R. W. (1996). Status of silicon carbide (SiC) as a wide-bandgap semiconductor for high-temperature applications: A review, Solid-State Electronics 39: 1409-1422.

Chase, M. W. J. (1998). NIST-JANAF Thermochemical Tables, 4th ed., ACS, AIP and NIST, New York, pp. 648-9.

Chaussende, D., Wellmann, P. J. \& Pons, M. (2007). Status of SiC bulk growth processes, J. Phys. D: Appl. Phys. 40: 6150-6158.

Cited from Choyke, W. J. (1960). Silicon carbide - a high temperature semiconductor, Pergamon Press, Oxford, p. xviii.

Dash, W. C. (1958). Silicon crystals free of dislocations, J. Appl. Phys. 29: 736.

Dolloff, R. T. (1960). WADD Tech. Report 60-143: 1-22.

Fromm, E. \& Gebhardt, E. (1976). Gase und Kohlenstoff in Metallen, II Daten, Spirnger-Verlag, pp. 730-33.

Giardini, A. A. \& Tydings, J. E. (1962). Diamond synthesis: Observations on the mechanism of formation, American Mineralogist 47: 1393-1421.

Hall, R. N. (1958). Electrical contacts to silicon carbide, J. Appl. Phys. 29(6): 914-917.

Hansen, M. \& Anderko, K. (1958). Constitution of binary alloys, 2nd Ed., McGraw-Hill, New York, pp. 353-365.

Hofmann, D. H. \& Müller, M. H. (1999). Prospects of the use of liquid phase techniques for the growth of bulk silicon carbide crystals, Mater. Sci. and Eng. B 61-62: 29-39.

Hurle, D. T. J., Mullin, J. B. \& Pike, E. R. (1967). Thin alloy zone crystallisation, J. Mater. Sci. 2: $46-62$.

Iguchi, Y. \& Narushima, T. (1993). 1st. Int. Conf. on Processing Materiasl for Properties, The Minerals, Metals \& Materials Society, pp. 437-440.

Inomata, Y., Inona, A., Mitomo, M. \& Sudzuki, H. (1968). Relation between growth temperature and the structure of $\mathrm{SiC}$ crystals grown by sublimation method, Yogyo-Kyokai-Shi 76(9): 313-319.

Inomata, Y., Inoue, Z., Mitomo, M. \& Tanaka, H. (1969). Polytypes of SiC crystals grown from molten silicon, Yogyo-Kyokai-Shi 77(3): 83-88.

Ishihara, K. N., Nishitani, S. R., Miyake, H. \& Shingu, P. H. (1984-5). Rapid solidification and the metastable phase diagrams of the fe-c, co-c and ni-c systems, Int. J. Rapid Solidification 1: 51-58.

Izhevskyi, V. A., Genova, L. A., Bressiani, J. C. \& Bressiani, A. H. A. (2000). Review article: silicon carbide. structure, properties and processing, Cerâmica 46: 4-13.

Kleykamp, H. \& Schumacher, G. (1993). The constitution of the silicon-carbon system, Ber. Bunsenges. Phy. Chem. 97(6): 799-805.

Knippenberg, W. F. (1963). Growth phenomena in silicon carbide, Philips Research Reports 18: 161-274.

Kresse, G. \& Furthmüller, J. (1996a). Efficiency of ab-initio total energy calculations for metals and semiconductors using a plane-wave basis set, Comput. Mat. Sci. 6: 15-50.

Kresse, G. \& Furthmüller, J. (1996b). Efficient iterative schemes for ab initio total-energy calculations using a plane-wave basis set, Phys. Rev. B 54(16): 11169-11186. 
Kresse, G. \& Hafner, J. (1993). Abinitio molecular-dynamics for liquid-metals, Phys. Rev. B 47(1): 558-561.

Kresse, G. \& Hafner, J. (1994). Ab-initio molecular-dynamics simulation of the liquid-metal amorphous-semiconductor transition in germanium, Phys. Rev. B 49(20): 14251-14269.

Kresse, G. \& Joubert, D. (1999). From ultrasoft pseudopotentials to the projector augmented-wave method, Phys. Rev. B 59(3): 1758-1775.

Liu, Z. \& Ni, J. (2005). Layered growth modelling of epitaxial growth processes for SiC polytypes, J. Phys.: Condens. Matter 17: 5355-5366.

Madar, R. (2004). Silicon carbide in contention, Nature 430: 974-975.

Medea-phonon (n.d.). http://www.materialsdesign.com/medea-phonon.htm.

Nakamura, D., Gunjishima, I., Yamaguchi, S., Ito, T., Okamoto, A., Kondo, H., Onda, S. \& Takatori, K. (2004). Ultra high-quality silicon carbide single crystals, Nature 430: 1009-1012.

Nishitani, S. R. \& Kaneko, T. (2008). Metastable solvent epitaxy of SiC, J. Crystal Growth 210: 1815-1818.

Nishitani, S. R., Takeda, R., Ishii, H., Yamamoto, Y. \& Kaneko, T. (2009). First principles calculations of vibrational free energy estimated by the quasi-harmonic approximation, J. Japan Inst. Metals 72(9): 566-70.

Nozaki, T., Yatsurugi, Y. \& Akiyama, N. (1970). Concentration and behavior of carbon in semiconductor silicon, J. Electrochem. Soc. 117(12): 1566-1568.

Oden, L. L. \& McCune, R. A. (1987). Phase-equilibria in the al-si-c system, Metall. Trans. A 18A(12): 2005-2014.

Okada, A., Miyake, H. \& Ozaki, R. (1981). Sructural changes of cast iron during heating at constant rate in the region of eutectic temperature and differential thermal analysis, J. Jpn. Foundrymen's Soc. 53(1): 9-14.

Olesinski, R. W. \& Abbaschian, G. J. (1984). The c-si(carbon-silicon) system, Bulletin of Alloy Phase Diagrams 5(5): 486-489.

Olesinski, R. W. \& Abbaschian, G. J. (1996). Binary Alloy Phase Diagrams, 2nd ed., ASM International, Materials Park, Ohio, pp. 882-3.

Ottem, L. (1993). SINTEF Report STF34 F93027.

Parlinski, K., Li, Z. Q. \& Kawazoe, Y. (1997). First-principles determination of the soft mode in cubic $\mathrm{zro}_{2}$, Phys. Rev. Lett. 78(21): $4063-4066$.

Perdew, J. P. \& Wang, Y. (1992). Accurate and simple analytic representation of the electron-gas correlation-energy, Phys. Rev. B 45(23): 13244-13249.

Rohmfeld, S., Hundhausen, M. \& Ley, L. (1998-I). Raman scattering in polycrystalline 3C-SiC: Influence of stacking faults, Phys. Rev. B 58: 9858-9862.

Scace, R. I. \& Slack, G. A. (1959). J. Chem. Phys. 30(6): 1551-1555.

Strong, H. M. \& Hanneman, R. E. (1967). Crystallization of diamond and graphite, J. Chem. Phys. 46: 3668-3676.

Suhara, S., Yuge, N., Fukai, M. \& Aratani, F. (1989). ZAIRYO TO PROCESS (Materials and Processes) 2(4): 1341.

Tairov, Y. M. \& Tsvetkov, V. F. (1978). Investigation of growth processes of ingots of silicon carbide single crystals, J. Cryst. Growth 43: 209-212.

Van Lent, P. H. (1961). The position of gray tin in the tin-mercury system, Acta Metallurgica 9: $125-128$. 
Verma, A. R. \& Krishna, P. (1966). Polymorphism and polytypism in Crystal, John Wiley and Sons, New York.

Wesch, W. (1996). Silicon carbide: Synthesis and processing, Nuclear Inst. Methods Phys. Res. B 116: 305-321.

Yanabe, K., Akasaka, M., Takeuchi, M., Watanabe, M., Narushima, T. \& Iguchi, Y. (1997). Materials Trans. JIM 38(11): 990-994. 


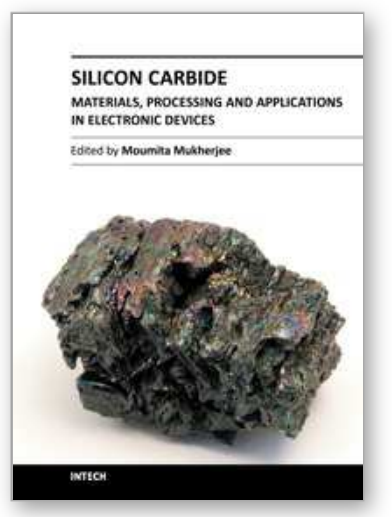

\author{
Silicon Carbide - Materials, Processing and Applications in \\ Electronic Devices \\ Edited by Dr. Moumita Mukherjee
}

ISBN 978-953-307-968-4

Hard cover, 546 pages

Publisher InTech

Published online 10, October, 2011

Published in print edition October, 2011

Silicon Carbide $(\mathrm{SiC})$ and its polytypes, used primarily for grinding and high temperature ceramics, have been a part of human civilization for a long time. The inherent ability of SiC devices to operate with higher efficiency and lower environmental footprint than silicon-based devices at high temperatures and under high voltages pushes SiC on the verge of becoming the material of choice for high power electronics and optoelectronics. What is more important, $\mathrm{SiC}$ is emerging to become a template for graphene fabrication, and a material for the next generation of sub-32nm semiconductor devices. It is thus increasingly clear that $\mathrm{SiC}$ electronic systems will dominate the new energy and transport technologies of the 21st century. In 21 chapters of the book, special emphasis has been placed on the â€œmaterialsâ€ aspects and developments thereof. To that end, about $70 \%$ of the book addresses the theory, crystal growth, defects, surface and interface properties, characterization, and processing issues pertaining to $\mathrm{SiC}$. The remaining $30 \%$ of the book covers the electronic device aspects of this material. Overall, this book will be valuable as a reference for SiC researchers for a few years to come. This book prestigiously covers our current understanding of $\mathrm{SiC}$ as a semiconductor material in electronics. The primary target for the book includes students, researchers, material and chemical engineers, semiconductor manufacturers and professionals who are interested in silicon carbide and its continuing progression.

\title{
How to reference
}

In order to correctly reference this scholarly work, feel free to copy and paste the following:

Shigeto R. Nishitani, Kensuke Togase, Yosuke Yamamoto, Hiroyasu Fujiwara and Tadaaki Kaneko (2011). Metastable Solvent Epitaxy of SiC, the Other Diamond Synthetics, Silicon Carbide - Materials, Processing and Applications in Electronic Devices, Dr. Moumita Mukherjee (Ed.), ISBN: 978-953-307-968-4, InTech, Available from: http://www.intechopen.com/books/silicon-carbide-materials-processing-and-applications-in-electronicdevices/metastable-solvent-epitaxy-of-sic-the-other-diamond-synthetics

\section{INTECH}

open science | open minds

\section{InTech Europe}

University Campus STeP Ri

Slavka Krautzeka 83/A

51000 Rijeka, Croatia

Phone: +385 (51) 770447

\section{InTech China}

Unit 405, Office Block, Hotel Equatorial Shanghai

No.65, Yan An Road (West), Shanghai, 200040, China

中国上海市延安西路65号上海国际贵都大饭店办公楼 405 单元

Phone: +86-21-62489820 
Fax: +385 (51) 686166

Fax: +86-21-62489821

www.intechopen.com 
(C) 2011 The Author(s). Licensee IntechOpen. This is an open access article distributed under the terms of the Creative Commons Attribution 3.0 License, which permits unrestricted use, distribution, and reproduction in any medium, provided the original work is properly cited. 